\title{
Ensuring Reliability of Transportation Vehicles with Redundancy Methods
}

\author{
Alexey Pavlov ${ }^{1 *}$, and Viktor Karagodin ${ }^{1}$ \\ ${ }^{1}$ Moscow Automobile and Road Construction State Technical University (MADI), 64 Leningradsky \\ prosp., Moscow, 125319, Russia
}

\begin{abstract}
The main questions of ensuring reliability of cars by methods of redundancy are considered. The problematic nature of reliability factor is confirmed by the analysis. Redundancy method is reviewed as responsible for solution of the problem when opportunities offered at every stage of "car life time" are used. Three basic principles of repair arrangement based on redundancy method are presented. These principles serve to bring into effect working capacity inherent in a design. The new redundancy techniques with use of repair kits is offered. The feasibility of integrated redundancy system is developed.
\end{abstract}

\section{Introduction}

Results of numerous researches by Dekhterinsky [1], Pronnikov [2], Ostreykovsky [3], Zorin [4], Karagodin and Mitrokhin [5], in the field of the organization and carrying out car maintenance and repair confirm that reliability of cars during their "life cycle" can be effectively provided only by the use of methods of complete redundancy.

\section{Main text}

Generally redundancy can be understood as "a way of ensuring reliability of object by use of additional resources and (or) opportunities, superfluous in relation to minimum necessary to enable workability".

Redundancy is one of the main methods to improve reliability of technical devices. This method allows, at leastin theory, to increase reliability of a device practically to an unlimited level.

Depending on a state the reserve components or devices are at the moment they come into operation, three types of a reserve are distinguished:

- hot reserve. Reserve elements perform the same function as a basic one, and their reliability does not depend on the moment they come into operation instead of the basic element.

\footnotetext{
* Corresponding author: 89037628407@mail.ru
} 
- Examples: additional driving axles of modern multi-axle full time trucks, or the coupled back wheels, double crank and camshafts of ICTs, etc.

- cold reserve. Reserve elements are in the idle state and in good working condition. This condition may vary when the element is in operation. Examples: the additional rising axles of truck-tractors, spare wheels, emergency pumps in houses, spare parachutes, emergency diesel power plants, transformers, compressors, generators, etc.

- warm reserve. Reserve and basic elements constitute the so-called "kinematic pair"; or reserve element serves as a redundant control or an executive mechanism. Reserve element could fail during waiting mode but less likely than a basic one. Examples: the duplicated controls of road-rollers, the duplicated controls of the machines used in dangerous operating conditions (direct and remote control at grinding mills, cranes, car lifts, etc.); the duplicating hydraulic cylinders at load-lifting devices of cars, etc.

The warm reserve is the most common type of redundancy, while hot and cold reserves are exceedingly rare.

From the examples given above, possibilities of use of the additional resources inherent in a design of a given vehicle are absolutely evident (in other words the first part of the foregoing reserve definition). However, the potentialities of redundancy alone are almost not considered.

In widely used classification of types of redundancy "structural redundancy" is considered to be a basic one. "Cold reserve" is one of the three main types of Structural redundancy -replacement of a faulty element for a spare one from the kit of spares.

In the works on reliability growth by Dekhterinsky, Norkinand Pavlov, $[6,7,8]$ is stated that mechanical systems subject to aging can be restored only with use of system of structural redundancy by repair methods:

- the hot operational reserve, i.e. increase of reliability of an item to the level excluding formation of critical defects which can cause non-repairable condition of an item during a certain operating time;

- coldoperational reserve - replacement of the failed elements of system elements by repair kits or, in certain cases, separate components.

Such approach expands concept of the principles of redundancy, which includes not only additional, but also the main devices, components and interdependences of items which can be designed and made redundantly reliable. However, both specified approaches cannot be considered exhaustive. Fast replacement of the failed components requires operations support facilities, qualified personal and logistic system to deliver the necessary repair kit to the right place and in due time. And finally, there must be a manufacturer of components and devices enjoying redundant reliability.

Thus, a redundancy system is required, which takes into account design, production, operation and vehicle repair factors to ensure reliability of transportation devices. This conclusion is supported by the approaches considered above though they are not holistic.

Indeed, the definition of a repair kit offered by Dekhterinsky, Norkin and Apsinsuggests $[9,10]$ that insufficient operability of an item can be compensated by replacement of the failedcomponents by repair kits. Consequently, it is possible to claim that lack of new spare parts, operations support facilities and qualified personal can be offset by the services of an independent car repair down to a substitution of a broken vehicle by a reserve one.

Let's designate integrated redundancy system (fig. 1) as the system of reservation which offers interchangeable methods of reserve providing the most effective means of ensuring reliability of vehicles.

It is generally thought that reliability is provided at design and production stage and then maintained during service life by means of repair. It is fairly specified by Dekhterinsky, Norkin, Zorin and Pavlov [11-20] that to ensure reliability of ageing vehicle at proper level, in fact, means to improve it constantly according to engineering standards. Noting ambiguity 
of maintainability concept, authors give the following definition: "Maintainability -ability inherent in design and health of multicomponent mechanical structure subject to ageing and determining feasibility and expedience of its restoration to operation standards by means of redundancy repair within specified running time".

The developed scheme of the considered integrated system of reservation is submitted in drawing herein after.

It is established that repair is the only way to ensure effective increase of vehicles working capacity and reliability lost during operation.

Every car-owner, corporate or private, can carry out inside repair using repair facilities or a servicing company. But in both cases it is necessary to provide repair backing-up to increase the efficiency of rescue and recovery operations, quality ensuring being of primary importance. Researches by Anopriyenko and Baurova confirm that quality of rescue and recovery operations is provided, primarily and mainly, technologically with consistent repair redundancy [21],

Three mechanisms form the basis of service and repair structure - unit repair, use of repair kits and complete replacement of components.

The method of unit repair is the most applicable at the operating enterprises. It allows to reduce significantly repairs time since a failed item is replaced completely, i.e. only assembly and dismantling operations are performed. It also saves waiting time and working hours. Such practice can be effective only if there is certain number of replacement units in stock.

Repair with use of repair kits is more expedient for application at specialized repair enterprise or car service.

Structural components can be replaced one-by-one or in kits. In the latter case, as Pavlov, Dekhterinsky, Norkin and Skripnikov [22] confirm, a ground should be given to a number and content of repair kits. Separate spare parts and repair kits can be purchased in a distribution network. Every car-owner is apt to stock repair kits and components of greater demand. In some cases alacking component or repair kit can be restored.

Restoration is possible if there is an appropriate operations support facility, qualified personnel as well as the specifications. If these conditions cannot be met a component or a repair kit should be transferred to a specialized automotive repair facility.

The activities of such facilities can be effective only if there are additional operations support capacity, spare parts for repair kits. That will ensure a component to repair is immediately replaced for a repaired or anew one from a warehouse.

Setting-up a reasonable integrated back-up requires to create a complex of the interconnected mathematical models allowing to estimate alternative options and to choose the best of them. One of possible methods of modeling is offered by Kireeva, Zhuravlev and Pavlov [23].

Let's consider an alternative to unit and kit repair methods. In the first case the technical service of the motor transportation enterprise is to have a substitute fund of units. Its cost and expenses correspond to $U_{a}$ per a single unit, and $U_{a} \cdot A$ if a number of units is A. Unit repair idle-time $t_{a}$ is the time required for removal and installation of the unit, provided there is a spare unit in a substitute fund at a warehouse. If the unit is lacking the time of repair will increase by size $t_{0}$ - a waiting time of a spare unit. Average annual costs of car repairs by a modular method will make:

$$
C_{g}^{a}=U_{a} \cdot A+\left\{\left(C_{t}+U_{p r}\right) \cdot t_{a} \cdot\left(1-P_{0}\right)+\left[C_{t} \cdot t_{a}+U_{p r} \cdot\left(t_{a}+t_{o}\right)\right] \cdot P_{0}\right\} \cdot N_{g},
$$

where $C_{t}$ - the cost of 1 hour of works on car repairs;

$U_{p r}$ - hourly average losses from idle time of the car;

$P_{0}$ - probability of absence of a spare unit in a substitute fund at a warehouse

$N_{g}$ - average annual number of the repaired cars. 
In case of a kit repair the technical service of the motor transportation enterprise should have a stock of reserve items in the form of repair kits. Costs and expenses of it are equal to $U_{k}$ per one k-kit t and $U_{k} \cdot A_{k}$ at quantity of k-kits equal to $A_{k}$. Suppose there is a set of $\mathrm{R}$ options to integrate separate items into repair kits. One of these options is $r \in R$ option. Replacement of separate detail is considered as a specific case of repair kit replacement, when akit consists of a single component. During kit repairs an idle time under repair will be $t_{k}$ time required for removal and installation of a kit, if spare parts for a kit are in stock. If they are not, time of repair will increase by size $t_{o k}$ - a waiting time of a k-kit. Average annual costs of car repairs by a kit- method at r-m option, with separate components integrated into kits, will make:

$$
C_{g}^{r}=U_{k} \cdot A_{k}+\left\{\left(C_{t}+U_{p r}\right) \cdot t_{k} \cdot\left(1-P_{0 k}\right)+\left[C_{t} \cdot t_{k}+U_{p r} \cdot\left(t_{k}+t_{o k}\right)\right] \cdot P_{0 k}\right\} \cdot N_{g}^{r},
$$

where $P_{0 k}$ - probability of absence in a warehouse of a substitute fund of k- spare kit; $N_{2}^{r}$ - average annual number of the repaired cars at r-m option integrated repair kits.

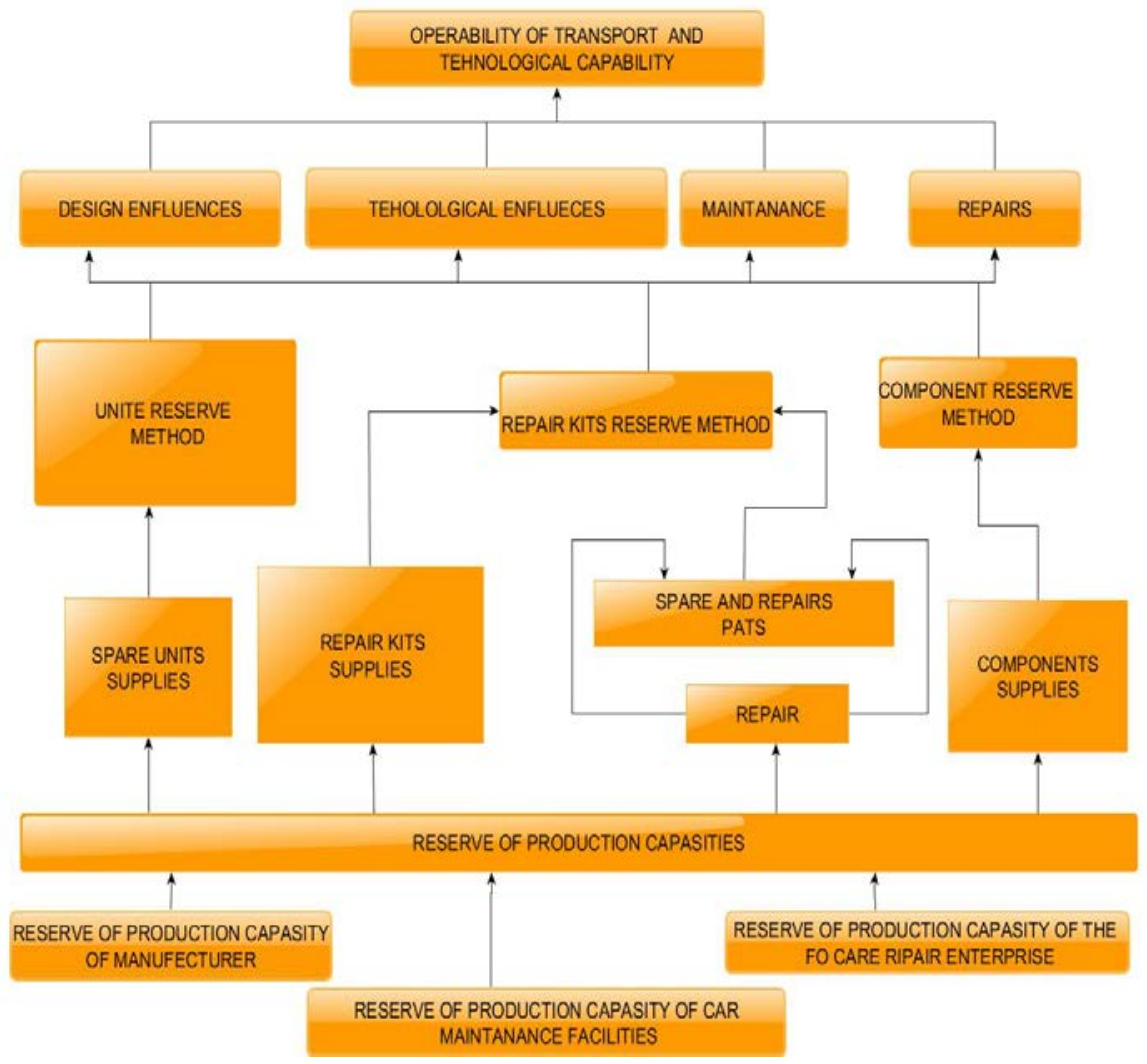

Fig. 1. Scheme of integrated redundancy system.

From all possible options the integration of details into kits $-r *$ option - is chosen as meeting a condition:

$$
C_{g}^{r^{*}}=\min _{r} C_{g}^{r},
$$

i.e. corresponding to a minimum of average annual costs of car repairs under condition that required gaps ("tightness") are restored - assuming that quality of repair and integration of repair kits are provided. 
The considered mathematical model is one of a range of the interconnected models allowing to estimate alternative options of redundancy and to choose the best one. For example, Baurova, Zorin, Prikhodko [24] suggest do this taking into account the influence of technological heredity when various materials are used for component production.

From the sequence of possible options the most effective is chosen to work out an integrated system of redundancy.

\section{Conclusion}

The use of the principles of structural redundancy( when the method of cold reserve is considered to be the basic one to ensure reliability of transportation vehicles repaired by reserve kits)makes possible to set up an integrated redundancy system of interchangeable back-up methods (from spare kitsand additional operations support facilities to specialized servicing companies). All of this is responsible for the most effective way to sustain reliability of vehicles.

The method of scientific reasoning of integrated redundancy system is developed on the basis of interconnected mathematical models. These models allow to carry out the system analysis of possible methods of alternative stock supplies.

\section{References}

1. Car repairs / under the editorship of Dekhterinsky L.V. - M: Transport, (1992)

2. Pro-nicknames, A.S. Nadezhnost of cars/Ampere-second. Pro-nicknames. - M.: ITS Media, (2012)

3. V.A. Ostreykovsky, Theory of reliability: Studies. for higher education institutions/VA. Ostreykovsky. - M.: The higher school, (2003)

4. V.A. Zorin, Nadyozhnost of mechanical systems. The textbook for HIGHER EDUCATION INSTITUTIONS. / V.A. Zorin. - M.: INFRA-M, (2015)

5. V. I. Karagodin, Car repairs and engines: the textbook for average special educational institutions / V. I. Karagodin, N. N. Mitrokhin. - M.: Skill; Vyssh. school, (2012)

6. L.V. Dekhterinsky, S.B. Norkin, A.P. Pavlov, Inductive expansion of expected and information model "Potential of Operability of Big System" / Problems of creation of information technologies: sb. nauch. tr., vyp. 7. - M.: Mezhdunarodn. academy of information technologies, p. 31-52. (2002)

7. L.V. Dekhterinsky, S.B. Norkin, A.P. Pavlov, Aksiomatik of the model "Potential of Operability of System", "Problems of Creation of Information Technologies" Collection of scientific works release 9, Smolensk, p. 105-110. (2004)

8. L.V. Dekhterinsky, S.B. Norkin, A.P. Pavlov, Ways of increase of efficiency of operation of cars//"Problems of creation of information technologies" Collection of scientific works release 15, MADI, p. 136-142, (2007)

9. L.V. Dekhterinsky, Model of aging and restoration of systems (cars, their units and components): studies. grant / L.V. Dekhterinsky, V.P. Apsin, S. B. Norkin. - M.: MADI, (1989)

10. V.P. Apsin, Optimization of strategy of replacements: studies. grant / Accusative V.P. Apsin L.V. Dekhterinsky, S.B. Norkin. - M.: MADI, (1991)

11. A.P. Pavlov, Justification of efficiency of application of strategy of operational reservation by method of use of repair kits / A.P. Pavlov, A.S. Perfilov//Motor transportation enterprise. No. 12. p. 50-52. (2011) 
12. L.V. Dekhterinsky, Iyerarkhiya of the replaced repair kits and expected model of operability of big system / L.V. Dekhterinsky, S. B. Norkin, A.P. Pavlov//Problems of creation of information technologies: sb. nauch. tr., vyp. 6. - M.: International academy of information technologies, p. 326-344 (2001)

13. L.V. Dekhterinsky, Potential of operability of big system / L.V. Dekhterinsky, S. B. Norkin, A.P. Pavlov//Problems of creation of information technologies: sb. nauch. tr., vyp. 5. - M.: International academy of information technologies, p. 87-101. (2000)

14. L.V. Dekhterinsky, V.A. Zorin The car repairs and the general regularities defining efficiency of its application//Problem of industrial car repairs and road cars: Collection of scientific works of MADI (TU). - M, Page 116-121. (1996)

15. A. Belyaev, A. Pushkarev, V. Kuzmichev Vehicle reliability and safety through simulation of the sequence of restoration of motor vehicle components. Transportation Research Procedia Volume 36, Pages 50-55 (2018)

16. F.H. Gandoman, A. Ahmadi, P.V. Bossche, J.V. Mierlo, N. Omar, A.E. Nezhad, H. Mavalizadeh, C. Mayet, Status and future perspectives of reliability assessment for electric vehicles. Reliability Engineering \& System Safety Volume 183, March 2019, Pages 1-16 (2019)

17. S. Repin, S. Evtiukov, S. Maksimov, A method for quantitative assessment of vehicle reliability impact on road safety. Transportation Research Procedia Volume 36, Pages 661-668 (2018)

18. V. Kurganov, M. Gryaznov, A. Dorofeev, Management of transportation process reliability based on an ontological model of an information system. Transportation Research Procedia Volume 36, Pages 392-397 (2018)

19. A. Kapustin, A. Terentiev, Rational Lifetime of a Vehicle in Terms of Ensuring Security of Its Design. Transportation Research Procedia Volume 20, Pages 254-260 (2017)

20. E. Rogova, G. Lodewijks, Braking system redundancy requirements for moving walks. Reliability Engineering \& System Safety Volume 133, January 2015, Pages 203-211 (2015)

21. A.K. Anoprienko, N.I. Baurova A bonded-riveted technique of fabrication and machine maintenance using hot-melt adhesives//Polymer Science - Series D. 2017. Vol.10. No. 3. p. 217-220. (2017)

22. A.P. Pavlov, L.V. Dekhterinsky, S.B. Norkin, S.A. Skripnikov Manual. The theory of potential of working capacity and repair reservation of reliability of the growing old technical systems Moscow "MADI" (2013)

23. S.V. Kireeva, The theory of casual processes and its application for modeling of processes of restoration of cars / S.V. Kireeva, S.G. Zhuravlev, A.P. Pavlov. - M.: MADI, (2013)

24. N.I. Baurova, V.A. Zorin, V.M. Prikhodko Determination of the synergetic effect of the damage accumulation process in polymer materials using catastrophe theory//Theoretical foundations of chemical engineering, 2016, Vol. 50, No. 1, p. 119125. (2016) 